\title{
A EXPERIÊNCIA HISPANO-AMERICANA DE Antonio Candido
}

\section{EnTrevistador: Pablo Rocca*}

Universidad de la República

N

dia 25 de setembro de 2004 fui recebido pelo professor Antonio Candido na sua casa, mercê à cordial intermediação do professor Jorge Schwartz. Para além de minhas expectativas, mantive com ele um diálogo que se prolongou ao longo de quatro horas, o qual depois foi gravado, transcrito e enviado ao entrevistado. Em 12 de julho de 2005, quando aconteceu um segundo encontro, o professor Candido me anunciou que ia me enviar uma versão mais extensa daquela entrevista. Uma semana mais tarde, recebi em Montevidéu o texto datilografado a dois espaços, com mínimas correções manuscritas, em quatorze fólios tamanho carta. Nesta ocasião acrescentou numerosos dados e opiniões, organizadas segundo a ordem da sua memória.

Este texto foi publicado, por única vez até agora, no livro Ángel Rama, Emir Rodriguez Monegal y el Brasil (Dos caras de un proyecto latinoamericano), Montevidéu, Banda Oriental, 2006, que originalmente foi minha tese de doutorado na USP, sob a orientação do professor doutor Jorge Schwartz. Aliás, este livro teve uma circulação muito restrita. De certa forma, então, trata-se de uma mescla de entrevista com questionário. Só foram tiradas as duas últimas perguntas que se

* Doutor em Letras (FFLCH-USP). Professor Titular de Literatura Uruguaia na FHCE, Universidad de la República, Montevideo. Diretor do Arquivo literário desta Universidade. Tradutor de Machado de Assis, Lima Barreto, Murilo Rubião, entre outros autores brasileiros. Alguns de seus livros: 35 años en Marcha, 1991; Horacio Quiroga, el escritor y el mito, 1996 (2ª ed. 2007); Poesía y política en el siglo XIX (Una cuestión de fronteras), 2003; Ángel Rama, Emir Rodríguez Monegal y el Brasil, 2006. 
afastavam do centro de gravitação do conjunto: a experiência hispano-americana do Antonio Candido.

PR: O sr. esteve no Uruguai em 1960. Foi a primeira viagem a um país da América Latina?

AC: Foi, e só dezenove anos mais tarde voltei a visitar outro, Cuba, onde estive durante quase um mês de cada vez em 1979 e 1981, além de uma semana em 1985. Aproveitei para fazer escala no Equador e três vezes no Peru, onde me demorei, visitei o interior e fiz bons amigos. No México estive quase um mês em 1980, mas Buenos Aires só conheci de passagem, numa escala de vôo em 1985. Dos países latino-americanos, aquele com o qual tive sempre, mesmo indiretamente, maior ligação espiritual foi o Uruguai, por causa de um episódio na vida de meu pai, Aristides Candido de Mello e Souza. Foi o seguinte.

No ano de 1908 o Ministério das Relações Exteriores mandou ao Uruguai uma missão de estudantes, entre os quais ele. Viajaram com passaporte diplomático e generosamente providos de libras esterlinas em ouro. Montevidéu tinha mais ou menos trezentos mil habitantes e os rapazes foram muito bem recebidos pela sociedade local, que era refinada e acolhedora segundo meu pai, então jovem estudante de medicina com vinte e dois anos. Em dado momento, o chefe da missão o encarregou de fazer um discurso de saudação. Como acontece às vezes na vida, ele estava inspirado e se saiu bem, obtendo sucesso e causando impacto. Isso lhe valeu certa voga, traduzida em relações cordiais e ofertas de livros. Tenho ainda um cartão do ilustre Juan Zorrilla de San Martín ao "talentoso joven Arístides Mello". Além disso Zorrilla lhe deu com dedicatórias amáveis seus livros Tabaré e Resonancias del camino. Teve relações com Carlos María Prando, que lhe ofereceu com longa dedicatória Motivos de Proteo [de José Enrique Rodó]; com Pablo Blanco Acevedo, que também lhe deu com dedicatória a sua pequena história do Uruguai; o mesmo fez o poeta César Miranda com Leyendas del alma. Quando fui a Montevidéu, mais de meio século depois, tive o prazer de encontrar pessoas que se lembravam de meu pai e falavam dele com carinho. Essa experiência de mocidade o marcou profundamente e ele a evocava sempre, criando em nossa casa uma espécie de simpatia especial pelo Uruguai. Por isso eu tinha vontade de conhecê-lo e aceitei prontamente o convite para dar um curso lá, mesmo sabendo que não estava à altura da tarefa.

Além disso, houve em minha família uma experiência uruguaia peculiar no ano de 1934, quando o presidente Gabriel Terra veio com grande comitiva tratarse de umas dores neurálgicas em Poços de Caldas, estação balneária do Estado de Minas Gerais de cujos Serviços Termais meu pai, especialista em reumatismo, era diretor na ocasião. Os uruguaios permaneceram mais de vinte dias, assistidos por uma missão especial do governo brasileiro, que pôs às ordens do presidente diplomatas e militares. Por delegação do governo de São Paulo, meu pai foi o representante oficial deste Estado. 
Terra era muito simpático e comunicativo. Veio com a esposa, uma filha, dois filhos, seu médico e ministro doutor Mañé Garzón, o senador Alberto Puig Larravide e outras pessoas, inclusive uma senhora idosa, nora do presidente Juan Idiarte Borda. Ela contou a minha mãe que o seu sogro havia sido assassinado durante uma procissão religiosa [25 agosto de 1897]. Terra deu a meu pai, além do seu retrato, alguns opúsculos de sua autoria, um dos quais sobre Mauá, de quem era grande admirador e do qual (salvo confusão da minha memória), sua senhora descendia.

Foi um período de grande movimento na pequena cidade, com o hino nacional uruguaio executado frequentemente pela banda de música local, com espetáculos e competições em homenagem ao presidente. Minha mãe ofereceu em nossa casa um chá a ele, sua família e membros da comitiva, tendo comparecido o embaixador uruguaio no Rio, que acabava de chegar a Poços de Caldas. Era parente de Pablo Blanco Acevedo e depois de alguma hesitação meu pai e ele se reconheceram e evocaram encontros em 1908, quando eram ambos estudantes. Essas coisas dão uma ideia da presença de seu país em nossa casa.

No começo dos anos de 1950 esteve em São Paulo Cipriano Santiago Vitureira, com quem me relacionei. Ele fez palestras, inclusive uma que me impressionou sobre a obra de Figari, ilustrada por diapositivos, dando-me vontade de ir a Montevidéu ver os originais, o que foi possível em 1960, quando meu amigo e colega Walter Wey, adido cultural da nossa embaixada e diretor do Instituto Cultural Uruguayo-Brasileño (ICUB), me levou à casa de uma das filhas do grande pintor, que possuía muitos quadros do pai.

PR: Como foi que recebeu o convite da Universidad de la República para participar dos cursos de verão?

AC: Naquele tempo havia um convênio entre as universidades de Montevidéu, Buenos Aires e Santiago do Chile para realizar esses cursos, um ano em cada lugar, e creio que costumavam convidar alguns estudantes e professores de outros países latino-americanos. Em 1959 Lourival Gomes Machado esteve em Montevidéu fazendo palestras e o grande reitor Mario Cassinoni lhe pediu que indicasse nomes para o curso de verão do ano seguinte, que seria lá. Lourival indicou o professor João Cruz Costa, de Filosofia, e eu. Recebi o convite com o tema já preestabelecido: "Unidade cultural da América Latina". Eu não estava preparado, porque não tinha conhecimentos suficientes, mas senti que era a oportunidade de realizar o desejo de conhecer a cidade tão importante na vida de meu pai. Aceitei, fiz o que pude e que poderá ser avaliado pelo que me disse o organizador dos cursos, José Pedro Díaz, com toda a franqueza, que o meu curso era interessante quanto ao método, mas revelava conhecimentos limitados. Como vê, "acertou na mosca"...

Mas os estudantes gostaram e estabeleci com eles boas relações, apesar da língua. Quando chegamos, o reitor Cassinoni nos disse: "Ustedes, por supuesto, 
van a hablar en español". Respondemos que não, e ele observou que os estudantes não entenderiam o português, sugerindo: "Hagan como su colega Lourival Gomes Machado, quien inventó una lengua llamada hispanogués". Foi o que fizemos, mas na última aula informei aos alunos que não poderia cometer o crime de falar naquela língua macarrônica sobre a obra de um autor ainda pouco conhecido fora do Brasil, Guimarães Rosa e seu livro Grande sertão: veredas. Falei pausadamente e todos compreenderam.

A propósito de língua, um parêntese divertido. Eu estava dando a primeira aula a um auditório numeroso, quando avistei no fundo da sala, prestando grande atenção, Vinicius de Moraes, que era vice-cônsul do Brasil. Terminada a aula nos encontramos alegremente como velhos amigos e ele perguntou qual era o horário do meu curso. Eu informei, dizendo que com certeza não iria assisti-lo, ao que respondeu: "Virei a todas as aulas. Você pensa que vou perder o espetáculo de vê-lo falando esta língua?" Mas não cumpriu a ameaça...

O professor Cruz Costa era amigo de Arturo Ardao, cuja família nos recebeu com encantadora cordialidade. Num jantar em casa de seus pais provei pela primeira vez um vinho uruguaio. Aprendi muito sobre a história de seu país com a irmã de Ardao, María Julia, e uma de suas colegas, cujo nome esqueci, ambas pesquisadoras da Casa de Rivera. Pude conversar com o diretor do Museu Histórico Nacional, Juan Pivel Devoto, com quem comentei o livro então recente de John Street, Artigas and the emancipation of Uruguay, que eu acabara de ler.

Além de rever Cipriano Vitureira, fiz boas relações com diversos intelectuais, inclusive José Enrique Etcheverry e Tabaré Freire. Este me deu obras de Carlos Reyles e Javier de Viana. Montevidéu tinha excelentes livrarias onde comprei não apenas muitos livros de autores uruguaios, como os de Alberto Zum Felde, que me foram muito úteis, mas também de brasileiros do passado, difíceis de encontrar aqui.

PR: Nesse momento Ángel Rama não era professor da Universidade. Como entrou em contato com ele?

AC: Conheci-o na casa de José Pedro Díaz, que convidou a mim e ao professor Cruz Costa. Lá estavam Ángel e sua esposa Ida Vitale. Simpatizamos imediatamente. Antes eu tinha conhecido seu irmão Carlos (com quem me encontrei mais tarde na França) numa reunião na casa do simpático diretor da Aliança Francesa, creio que também adido cultural da embaixada de seu país. José Pedro e sua esposa Amanda Berenguer me deram seus livros e números de Entregas de la Licorne. Li com interesse a tese de José Pedro sobre Gérard de Nerval e seu livro sobre Gustavo Adolfo Bécquer. Nunca mais os revi, como não revi Ida Vitale, poetisa de boa qualidade, cujo segundo marido, Enrique Fierro, foi meu aluno no curso de verão.

Ángel foi um dos homens de maior magnetismo pessoal que conheci. Tinha uma flama interior que envolvia e contagiava o interlocutor ou o ouvinte. Ele me convidou para colaborar em Marcha (o que não fiz) e passou a remetê-la regular- 
mente quando voltei ao Brasil, além de mandar volumes de literatura uruguaia. Estabelecemos correspondência e não esqueço o que me disse na ocasião: que a tarefa maior dos intelectuais latino-americanos era trabalhar pelo intercâmbio entre os nossos países, e ele pretendia dedicar-se a isso. Muitos anos depois informou que desenvolvera o interesse pela Literatura Brasileira devido ao nosso encontro em Montevidéu.

Em 1965 nos encontramos num congresso em Gênova. Quando estava dirigindo a Biblioteca Ayacucho, nos anos de 1970, promoveu uma reunião em Caracas para a qual convidou Caio Prado Júnior e eu. Caio, que estivera preso mais de um ano pela ditadura militar, não obteve o visto de saída. Eu então me solidarizei com ele e também não fui. Em 1973 nos encontramos num congresso de Literatura Comparada no Canadá e a seguir ele foi convidado no mesmo ano, por sugestão minha, para fazer palestras na Universidade de São Paulo. Veio em dezembro com Marta Traba, que ficou nossa amiga.

As palestras de Ángel aqui foram um sucesso estrondoso. O grande auditório esteve sempre lotado e raras vezes vi um fenômeno igual de comunicação com o público, que parecia eletrizado. Naquela altura estávamos publicando a revista Argumento, que a ditadura militar sufocou no quarto número. Ángel e Marta se interessaram pela nossa tentativa de resistência por meio da revista, participaram de reuniões da comissão de redação e publicaram artigos nos números 3 e 4 . Para contornar a repressão, pensamos em fazer uma publicação bilíngue fora do Brasil, englobando escritores latino-americanos. Ángel se interessou pelo projeto, que afinal não prosperou. Em 1979 me convidou para um encontro no Wilson Center, mas surgiram problemas e eu não pude ir, enviando um texto que foi lido por Roberto Schwarz. Em 1980 estivemos juntos no México, num encontro organizado por Leopoldo Zea. Creio que no mesmo ano ele veio a um encontro na Universidade de Campinas, à qual voltou em fins de 1983 para uma reunião coordenada por Ana Pizarro, como primeira etapa na preparação da obra coletiva por ela dirigida sobre literaturas latino-americanas. Em 1982 houvera para o mesmo fim uma reunião em Caracas, à qual não pode comparecer porque lhe negaram visto nos Estados Unidos. Fizemos um protesto, e de volta ao Brasil escrevi um artigo no mesmo sentido.

PR: A correspondência e o contato pessoal com Rama foram mais contínuos depois da saída dele do Uruguai?

AC: De fato, tivemos mais contato depois que teve de deixar o Uruguai devido à ditadura. Lembro sempre de uma carta de 1973 na qual fala do golpe no Chile, dizendo: "En Chile se armó una inmensa ratonera, que atrapó lo que tenemos de mejor en América".

Na reunião de Campinas, no começo de outubro de 1983, Ángel e eu fomos indicados para fazer a síntese e a sistematização das discussões, com vistas ao plano final. Viemos então para São Paulo juntos e ele ficou hospedado em nossa 
casa, onde trabalhamos intensamente durante cinco dias. Mas precisaríamos fazer uma segunda sessão para o relatório final. Combinamos então que no começo de 1984 eu iria para este fim a Paris com minha mulher e ficaríamos hospedados no apartamento dele. Mas um mês e meio depois houve a catástrofe.

Sua última estadia aqui foi muito agradável. Fomos a casas de amigos comuns, ele mandou xerografar diversos livros de minha biblioteca e comprou outros, com a sua grande avidez de conhecer sempre mais e mais. Lembro que saímos juntos um dia com Jorge Schwartz e ele adquiriu a edição Aguilar de Machado de Assis, do qual dizia que era o maior romancista latino-americano do século XIX, sendo o maior poeta José Hernández.

PR: Rama conhecia muito bem a literatura hispano-americana naquele ano de 1960, e o Sr., naturalmente, a brasileira. O Sr. tinha amplas leituras hispano-americanas naquele momento?

AC: Começo pelo começo. A biblioteca de meus pais era boa, mas quase não tinha livros hispano-americanos. Além dos livros uruguaios que citei, havia alguns argentinos contemporâneos. Meu pai (que morreu relativamente cedo) gostava do Facundo e minha mãe era leitora de Las lenguas de diamante, de Juana de Ibarbourou. Mas a partir de certo momento, talvez 1938 ou 1939, argentinos e uruguaios começaram a fazer estadias de inverno em Poços de Caldas, uma espécie de season rioplatense. Alguns eram clientes de meu pai, voltavam cada ano, estabeleceram relações e costumavam dar e mandar revistas e livros de seus países. Assim, li muitos números de Nosotros, dirigida por Roberto Giusti, numa espécie de iniciação à literatura argentina. Nos anos de 1940, já em São Paulo, li bastante a revista Sur. Nos de 1950 mergulhei mais ou menos fundo pela primeira vez nas literaturas latino-americanas de língua espanhola, estimulado por um romance e um livro de política: Nostromo, de Joseph Conrad, e Les démocraties de l'Amérique Latine, de Francisco García Calderón. Adquiri então certo conhecimento da história e da cultura de nossa América graças à admirável coleção Tierra Firme, do Fondo de Cultura Económica, que funcionou como grande empresa de aproximação mental entre os nossos países. Para mim, foi um inestimável manancial.

Portanto, quando fui ao Uruguai já tinha algum conhecimento, o que possibilitou organizar mal-e-mal o curso sobre o tema que me deram. Nos anos de 1960 tive outra fase de leitura intensiva, estimulado pelo livro de Luis Harss, Los Nuestros, que me revelou a narrativa do boom. Mas nunca tive em relação às literaturas latino-americanas o conhecimento e a familiaridade que Ángel teve com a brasileira.

\section{PR: Tanto assim?}

AC: Sim. Era surpreendente. Vou dar um único exemplo. Nos anos de 1970 ele me pediu para fazer a lista dos títulos brasileiros para a Biblioteca Ayacucho. 
Eu fiz, e mais tarde Darcy Ribeiro interveio, propondo outros títulos, inclusive uma seleção de escritos de Sílvio Romero. Eu concordei, mas Ángel aceitou com certa relutância, comentando em carta: "A mí no me simpatiza Sílvio Romero por el libro que escribió contra Manuel Bomfim". Ora, o livro de Manuel Bomfim (de 1905) era então pouco conhecido aqui, e o de Sílvio, praticamente ignorado, pois é obra menor que nem os especialistas leem...

\section{PR: Rama estimulou seu trato com a literatura hispano-americana?}

AC: Creio que falamos pouco a respeito. Mas ele é responsável pelo meu ensaio mais conhecido na América espanhola, ensaio que me levou a aprofundar as leituras no setor. Foi o seguinte. Em 1968 fui professor visitante na Universidade de Yale, onde dei entre outros um curso de Literatura Comparada intitulado "A representação do espaço na ficção naturalista". Nele incluí Doña Bárbara, de Rómulo Gallegos e La vorágine, de José Eustasio Rivera, romances de segunda ordem bastante aborrecidos, mas não tive coragem de abordar livros do boom, a respeito dos quais ainda não me sentia seguro. Naquela altura houve uma reunião promovida, creio que no México, pela Unesco a fim de planejar a obra que se chamou depois América Latina en su literatura. Parece que me convidaram, mas não recebi a comunicação em Yale. Nessa reunião, ao distribuírem as tarefas, Sérgio Buarque de Holanda propôs o meu nome para um determinado tópico, mas Ángel (que era seu amigo) interveio dizendo: "Para Antonio Candido tengo un tema: Literatura y subdesarrollo". Sérgio assumiu então o compromisso em meu nome, e eu, para não desautorizá-lo, aceitei a contragosto, porque achei a tarefa muito superior às minhas possibilidades. O curioso é que nem Ángel nem Sérgio, que trabalharam no planejamento, colaboraram no volume, mas me fizeram colaborar...

Posso dizer que foi o artigo mais trabalhoso que escrevi. Labutei nele doze meses para me ajustar ao assunto difícil e reunir as informações, mas nesse processo aprofundei bastante o conhecimento. O resultado dever ter sido satisfatório, porque o organizador, César Fernández Moreno, o publicou em tradução francesa nos Cahiers d'histoire mondiale antes do livro sair, e além disso o fez reproduzir no Correio da Unesco numa quantidade de línguas.

PR: Dessa experiência de trabalho saiu a noção de "super-regionalismo"? Daí, outra pergunta: este conceito prefigura a noção de "transculturación" de Rama?

AC: Quanto à primeira parte, a resposta é sim. Quanto à segunda, creio que ele deu uma formulação mais completa e elucidativa no problema que procurei caracterizar como "super-regionalismo". É a sua teoria da fusão dos "dois modos", contribuição de grande originalidade e, a meu ver, a mais perfeita formulação sobre o assunto. No ensaio intitulado "O olhar crítico de Ángel Rama" termino sugerindo como ele foi além do meu ponto de vista: "Isso (a fusão dos «dois 
modos») foi sem dúvida uma criação própria do nosso universo literário, e ao defini-lo tão lucidamente Rama deu formulação madura e superior a pontos de vista que tinham sido percebidos por outros (no caso, eu) de maneira parcial e incompleta, e nunca tinham sido expostos com originalidade, força integradora e capacidade explicativa tão fortes".

PR: Foi na sua permanência em Yale que conheceu o crítico uruguaio Emir Rodríguez Monegal?

AC: Não. Quando estive em Montevidéu Walter Wey me falou bem a seu respeito, mas não o vi porque estava na Inglaterra. Eu o conheci ligeiramente em 1965 no congresso do Columbiarum em Gênova, ao qual já fiz referência. Mas creio que nem chegamos a conversar. No entanto, tempos depois, em 1968, tive alguma interferência no seu destino do seguinte modo: em Yale, meu grande amigo Richard Morse, historiador especializado na América Latina, que era professor lá, me disse que estavam pensando em convidar Monegal, mas o problema era que ele não tinha doutorado, e pediu a minha opinião. Eu lhe disse que achava a escolha excelente, e que a falta de doutorado correspondia aos hábitos do Uruguai, onde esse grau não era requisito, conforme eu tinha verificado quando dei o curso de verão em 1960. Morse perguntou se eu poderia explicar isso oficialmente por escrito, para servir de elemento auxiliar da decisão dos responsáveis, e eu então fiz um relatório. Em seguida Monegal foi convidado, é claro que não por causa disto, pois havia elementos mais importantes de convicção e ele tinha grande prestígio.

PR: Esta recomendação foi o começo de uma amizade ou de um maior relacionamento? A pergunta não é inocente, por causa da grande distância pessoal entre Rama e Rodríguez Monegal.

AC: Nunca soube se Monegal foi informado da minha intervenção. Quanto a seu relacionamento com Rama, sei que era tenso, mas os vi tratarem-se de maneira civilizada no congresso de Literatura Comparada do Canadá, em 1973, quando nós três e mais um colega brasileiro compusemos uma mesa sobre narrativa. Nessa ocasião foi que convivi um pouco com Monegal, que era boa companhia. Depois ele veio mais de uma vez a São Paulo e nos encontramos, sempre cordialmente, mas nunca fomos amigos e pude observar desde Gênova que as suas posições políticas não coincidiam com as minhas nem com as de Rama.

Assisti a algumas aulas que deu na Universidade de São Paulo. A sua maneira de expor era brilhantíssima e temperada pelo senso de humor, mas meio histriônica. Eu pensei com os meus botões: "O Uruguai tem professores extraordinários". Li alguma coisa dele, inclusive sobre Borges, e creio que é sem dúvida um crítico de valor, mas não tem a originalidade nem a força de pensamento de 
Ángel. Em 1973, a convite dele, realizei em Yale uma conferência e alguns seminários.

PR: Em que época teve contato com a obra de Borges?

AC: Creio que li as primeiras referências a ele nas revistas argentinas que davam a meu pai, e mais tarde em Sur, mas o certo é que não prestei atenção, até que em 1961 uma professora argentina que assistiu um curso meu sobre Teoria do Romance me ofereceu Ficciones, que foi uma revelação. Na mesma altura, Décio de Almeida Prado me falou dele com entusiasmo e eu me pus a lê-lo nos pequenos volumes cinzentos da Editora Emecé. É um escritor fascinante, mas devo dizer que não tenho por ele a admiração quase fanática que despertou no Brasil. Com risco de dizer uma heresia, penso que é um grande escritor menor. Eu pude conversar como ele num jantar, quando veio a São Paulo receber um prêmio.

PR: O Sr. chegou à Antropologia antes de Ángel Rama, que se aproximou com ela por volta de 1970. Penso em Os parceiros do rio Bonito e tantos artigos nos quais trabatha com ideias e noções de origem antropológica.

AC: A Sociologia e a Antropologia estão na base da minha formação universitária, porque sou licenciado em Ciências Sociais e Políticas e o livro que mencionou foi a minha tese de doutorado. Embora tenha sido assistente de Sociologia por dezesseis anos, praticava ao mesmo tempo a Crítica Literária, a princípio com forte viés sociológico e mesmo político. Obtive também um doutorado em Letras em concurso de Literatura Brasileira, de modo que tive por muito tempo os pés em duas canoas, como dizemos aqui, até que a partir de 1958 pude realizar o velho desejo de me transferir para o setor universitário de Letras, graças a este segundo título.

Nunca me considerei sociólogo, mas apenas professor de Sociologia durante certo tempo, e na verdade a Antropologia me atraia mais. Sobretudo a Antropologia Social dos ingleses. No meu tempo de moço, anos de 1930 e 1940, a Sociologia era aqui uma disciplina de ponta, que parecia servir de chave para tudo. Eu então optei pelas Ciências Sociais, porque desejava entender bem a sociedade brasileira e porque achei que elas me punham perto do socialismo, mas a Literatura foi sempre o meu campo predileto. Eu encarava a Sociologia mais como "ponto de vista", que me ajudou inclusive a ver a produção literária na sua interseção com a sociedade. A dimensão social me interessa, mas apesar do que muitos pensam e dizem, não sou um "crítico sociológico", porque procuro variar os instrumentos conforme a natureza dos textos.

Da Antropologia extraí as noções de estrutura e de princípio estrutural, pensando sobretudo em conceitos de Radcliffe-Brown. Estrutura para mim não é a dos estruturalistas. É o equilibro dinâmico das relações internas do texto, formando o substrato da camada aparente. Vista na dimensão da história, a estrutu- 
ra poderia ser concebida como sistema, que vejo como algo diverso do uso desta palavra pelos formalistas russos, isto é, não como algo interno à obra, mas como um conceito externo, válido para compreender a Literatura como conjunto de obras. Procurei aplicar este conceito à Formação da literatura brasileira e fui quase sempre mal compreendido. Ángel Rama foi dos poucos que entenderam o que eu quis fazer, e aliás utilizou muito bem o conceito. 